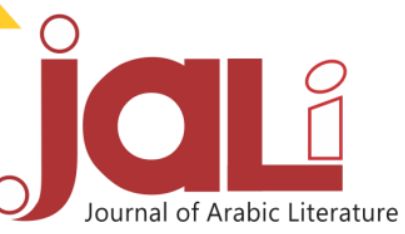

DOI $\quad: \underline{10.1886 / j a l i . v 1 i 2.8445}$

ISSN : 2722-5585

\title{
Vol. I-2
}

\author{
الأسلوب التقابلي في سورة البقرة ودلالثه \\ Anisa Rosi Oktaviana \\ Universitas Islam Negeri Sunan Ampel Surabaya \\ Email:anissarosi689@gmail.com
}

\begin{abstract}
The purpose of this study is to explain and identify the conflicting meanings in Arabic. It refers to the Muqabalah Theory in Balaghah, and At-Tadzat in Semantics using Ali Al-Khouli's opinion, there are also different patterns of sentence contradiction, which justifies the importance of this study. The data were obtained from AL-Qur'an Surah Al-Baqarah. This research employs a descriptive qualitative method. In Balaghah At-Taqabuly or Al-Muqabalah is a sequence of contradictory meanings; while in the Semantics, it is called At-Tadzat which literally means Antonym. In line with the At-Taqabuly or Al-Muqabalah, it has no special division. But in semantics, there is a difference between the old meaning and the new meaning. In the old meaning, At-Tadzat is interpreted as a different word but has the same meaning, and conversely Ali Al-Khouli interpreted AtTadzat as 2 opposing words which are the understanding of At-Tadzat in a new meaning. At -Tadzat is divided into 9 parts: 1) Al-Had, 2) Al-'Aks, 3) Al-Mutadarrij, 4) Al-Imtidadi, 5) Al-'Amudy, 6) Al-Juz'i, 7) Al -Dairi, 8) Al-Rutbi, 9) Al-Intisab. In this study only found 5 types of At-Tadzat namely Al-Had, 2) Al-'Aks, 3) AlMutadarrij, 4) Al-Imtidadi, 5) Al-'Amudy. The study found 10 syntactic patterns of meaning opposition of the Surah of Al-Baqarah, Ism Maushul, Idhofah, Jar Majrur, Anwa 'Al -otal, Maf'ul bih, Ism Inna, Na't wa Man'ut, At-Tamyiiz, Al-Hal, and Muabtada wa Khabar.
\end{abstract}

Keywords: Al Uslub At-Taqabuly, Antonym Structure, At-Tadzat, Surat AlBaqarah 
متوافقين أو أكثر، ثم يؤتى بما يقابل ذلك

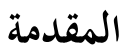

على الترتيب.

وللتقابل أنواع عديدة من اللفظ وصور

مختلفة من التعبير وردت في دراسات

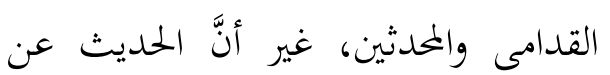

التقابل وأنواعه يقودنا إلى الحديث عن أسماء

وتراكيب لمفاهيم تكاد تصب في بحرى

واحد، فهي جميعا -بالرغم من فروقها

الدلالية - تتحدث عن اجتماع شيئين أو في وروفي

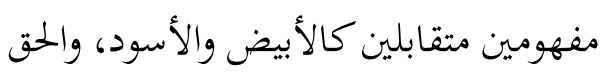

$$
\text { والباطل، والأول والآخر. }
$$

أن الأساليب المتقابلة في الصور

القرآنية قد تختلف طولًا وقصرًا وقد تتساوى الإيل

فيما بينها، ينشأ اختلاف بين أسلوبين طولًا

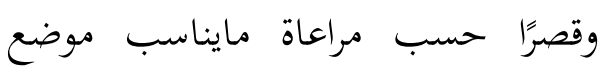

السورة والسياق الذي يعرضان فيه. ولم

يكتفي القرآن الكريم في وضع اللفظ بمراعاة

السياق الذي وردت فيه بل راعى جميع

المواضع التي وردت فيها اللفظ ونظر إليها نظرة واحدة شاملة في القرآن الكريع كله،

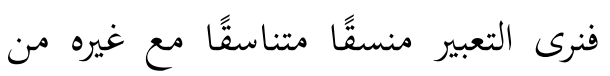
التعبيرات كأنه لوحة فنية واحدة متكملة.

وهناك علم أخر يدرس عن المعنى وهو

كعلم الدلالة. قال عمر (1991 1) في كتابه
القرآن بجمال أسلوبه و معانيه، لم

يكشف كثير من أسرار ما فيه من القرآن،

خصوصا عن أسلوب جمله. ومن ظواهر

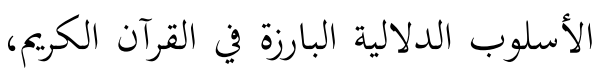

ومن أوجه الفنّية في بلاغته، ظاهرة التقابل.

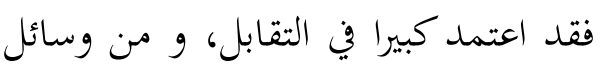

الكثيرة جعله وسيلة لتوضيح المعاني.

لاتقلّ دراسة في جمالية أسلوب القرآن

على متمكنين اللغة خصوصا متمكنين اللغة

العربية. والإطار النظري الذي استخدمهم

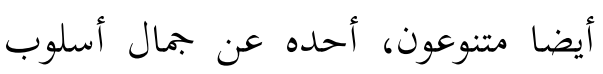

القرآن هو علم البلاغة. في علم البلاغة

ثلاثة أقسام: الذي يدرس عن إبراز المعنى

الواحد في صور مختلفة وتراكيب متفاوتة في

وضوح الدلالة مع مطابقة كلّ مقتضى الحال

يسمى بعلم البيان، ثم الذي يبحث عن

المعنى أي أصول وقواعد يعرف بها كيفية مطابقة الكلام لمقتضى الحال وهو علم المعاني، الأخير هو علم البديع تزيين الألفاظ

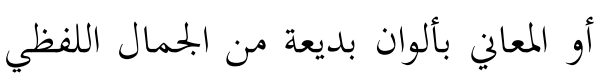

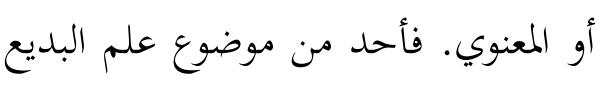
هو المقابلة أو التقابل أن يؤتى بمعنيين 
تتكون اسما اسما والجملة تحت الخطط الثانية تتكون من اسمان مفعولان لتعبير أن هناك شيئين يقابل بعضه عن الآخر بجانب نفهمه من جهة المعنى لكن وجود الأوزان المتفرقة كذلك.

فتأسيسا على ما سبق كان من أبرز

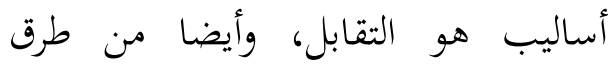
للوضوح والجمال. فاخترت الباحثة الموضوع "الأسلوب التقابلي في سورة البقرة ودلالته". وهذا البحث يراد به كشف عن التقابل

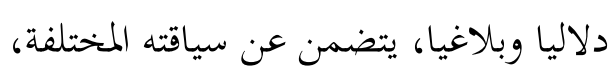
أشكاله المتنوعة.

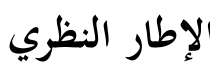

يعرف بعض علماء اللغة بأن علم الدلالة هو دراسة المعنى أو علم الذي لِي يدرس عن المعنى أو الفرع الذي يدرس الذس الشروط الواجب ليوافر الرمز حتى قادرا على حمل المعنى. وقال الجرجاني:"كون الشيء بحالة يلزم من العلم به العلم بشيء آخر، والشيء الأول هو الدال، والثاني المدلول
علم الدلالة "يعرف بعض علماء اللغة بأن علم الدلالة هو دراسة المعنى أو علم الذي

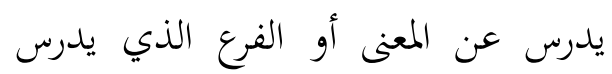
الشروط الواجب ليوافر الرمز حتى قادرا على لئ لهري

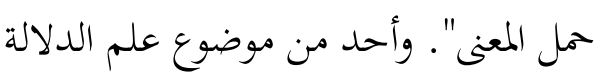
هو التضاد أي الأضدد عند علماء اللغة المحدثين التضاد هو وجود لفظين يختلفان نطقا و يتضدان معنى. على المخطوط نعرف أن في سورة البقرة يشرح عن المؤمن والكافر. وغير هذا يبحث عن الثواب لمن عمل ما أمر الله

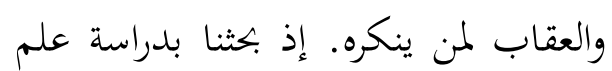
البلاغة فهو يدل على دراسة علم البديع

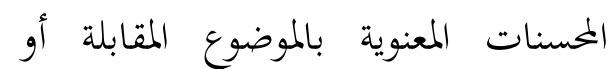
التقابل. ومن جهة علم الدلالة يدل في الدراسة التضاد.

وُجدد الآيات التقابلية في سورة البقرة ليس فقط يقابل كلمة كلمة المثال: الحي والموت، المؤمن والكافر، بل وجدت الباحثة

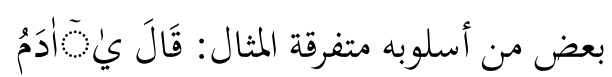

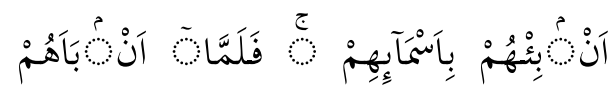

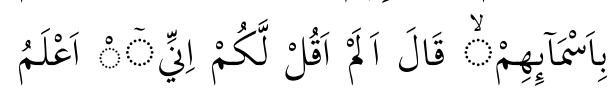

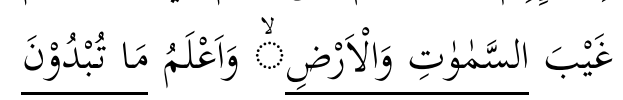

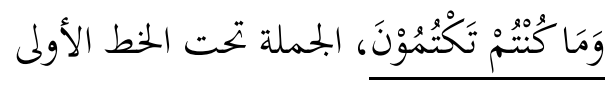


ثم نستمرّ إلى الأسلوب، نشأ علم

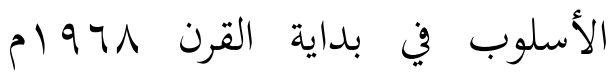

بالتطور الذي لحق الدراسات اللغوية في

القرن الماضى، مما يجعل من الضروري

إلقاء نظرة خحاطفة على هذا التطور،

لمعرفة أهم مراحل ومكوناته، والعوامل

الفاعلة فيه، مما أدى إلى مولد علم

الأسلوب. للأسلوب ثلاثة أنواع:

الأسلوب العلمى، الأسلوب الأدبى،

الأسلوب الخطابى. وههنا استخدمت

الباحثة الأسلوب الأدبي وهو في علم

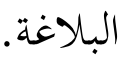

وينقسم البلاغة إلى ثلاثة أقسام :

علم البيان، وعلم المعاني، وعلم البديع.

بل الباحثة سيركز بحثه في علم الديع

على باب "المقابلة \التقابلي". المقابلة

هو أن يؤتى بمعنيين متوافقين أو أكثر، لوكابك

تم يؤتى بما يقابل ذلك على الترتيب.

فمن التعريف السابقة عن معنى

الأسلوب و التقابل، استنبط الباحثة

بأن أسلوب التقابلى هو المعنى المصوغ
احدى مشكالات في علم الدلالة

هي تعدد المعنى كالمشترك اللفظ، الترادف، والتضاد. اهتم الباحثة هنا في مشكلة تعدد المعنى على التضاد. عند علماء اللغة المحدثين التضاد هو وجود لفظين يختلفان نطقا و يتضدان معنى، رأي علي الخولي أن للتضاد تسعة أنواع: التضاد الحد (المثال: حي - ميت )،

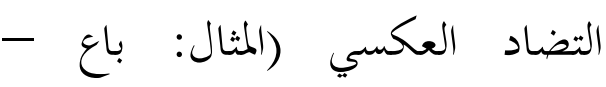
اشترى)، التضاد المتدرّج (المثال: سهل - صعب)، التضاد العمودي (شمال شرق، شثال - غرب)، التضاد الامتدادي (المثال: فوق - تحت)، التضاد الجزئي (المثال: غلاف -

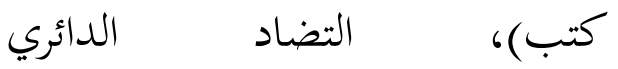
(المثال:السبت، الأحلد، الإثنان،

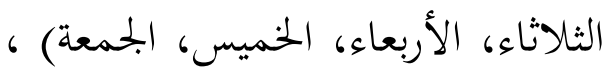
التضاد الرُّبي(المثال: العميد، نائب العميد الأول الثاني الثالث)، التضاد الانتسابي(المثال: موز برتقال تفاحة). 
في البيان السابق ظهر نظريتين في

ميدان علم البلاغة في علم البديع على باب

المقابلة و على نظرة علم الدلالة في باب

التضاد.

وهنا تحليل الأسلوب التقابلي في

$$
\text { بعض سورة البقرة: - مض }
$$

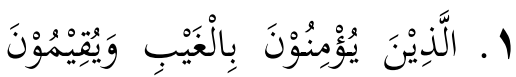

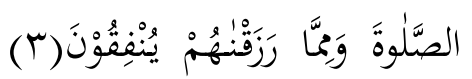

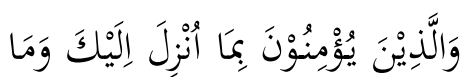

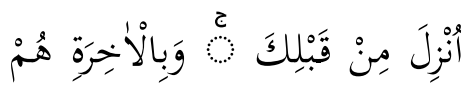

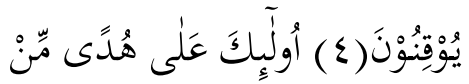

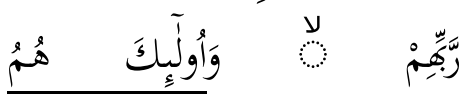

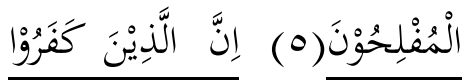

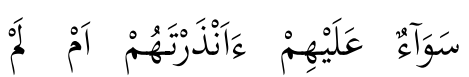

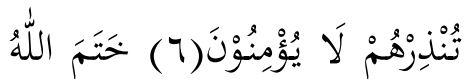

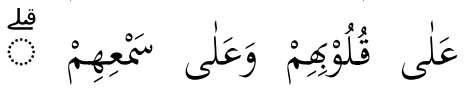

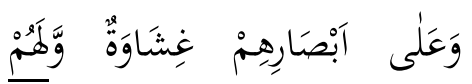

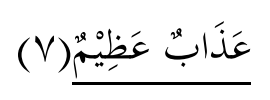

هناك لفظين التقابلين التَّذينْ

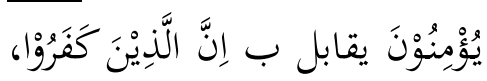

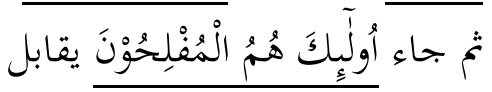

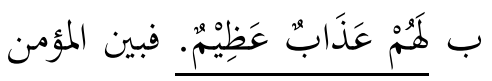

والكافر دالة على التضاد الحاد.
في ألفاظ المقابلة، أو طريقة التعبير عن الألفاظ التقابلية.

واختارت الباحثة سورة البقرة لينال

البيانات عن التضاد والمقابلة فيه.

\section{منهجية البحث}

ينقسم منهج البحث قسمين

عاما وهما منهج البحث الكمي لنمي والبحث النوعي أو الكيفي. كان هذا البحث بحثا نوعيا الذي من أهم سماته أنه لا يتناول بياناته عن طريقة معالجة رقمية إحصائية. وأما من حيث نوعه فهذا البحث من نوع البحث التحليل التقابلي وخاصة من ناحية الأسلوب التقابلي في سورة البقرة وبلاغته.

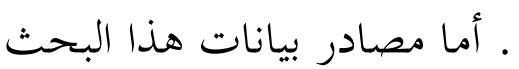

هي من الكلمات والنصوص في في

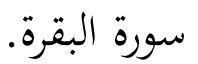
النتائج

1. الأسلوب التقابلي في سورة البقرة ودلالته 
وكذلك وجددت الأسلوب التقابلي

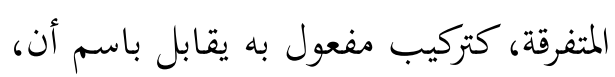
كما في الأية الرابعة وعشرين "فَانْ لُّمْ تَفْعَلُوْا

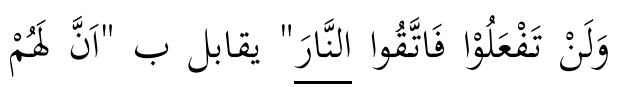

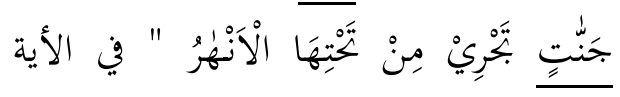
الخامسة وعشرين.

الاختتام

بعد أن بحثت الباحثة عميقا عن

هذا الموضوع، أذخذت الباحثة الاستنباط.

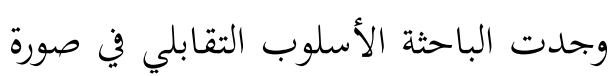
البقرة أي المقابلة في الدراسة البلاغية. وفي علم الدلالة نعرفه ب التضاد.

للتضاد عند علي الخولي تسعة أنواع: التضاد الحاد، التضاد العكس، التضاد المتدرج، التضاد الامتدادي، التضاد العمودي، التضاد الجزئي، التضاد الدائري،

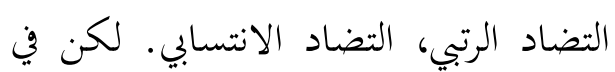

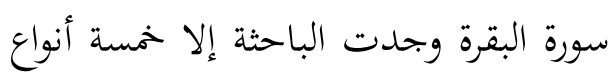
وهو التضاد الحاد، التضاد العكس، التضاد

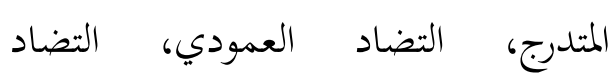
الامتدادي، التضاد الجزئي، التضاد الرتبي،

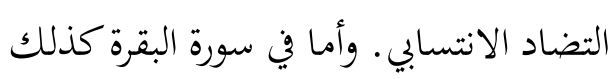
وجدت الباحثة أوزان تركيب الكلمة المتفرقة

\section{r. فَجَعَلْنُهَا نَخَالَا لِّمَا بَيْنَ يَدَيْهَا

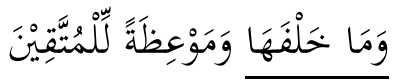

الأسلوب المتقابلى واحد بين لفظ لِّمَا

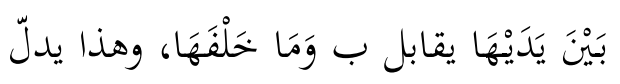
على التضاد الامتدادي.

\section{أوزان الأسلوب التقابلي في سورة

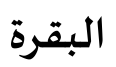
في مرور تحليل البيانات وجد الباحثة شيء أخر هو عن الأوزان الأسلوب التقابلي في سورة البقرة. وجدت الكلمة المتضادة يشمل على الأوزان المتنوعة، منهم:

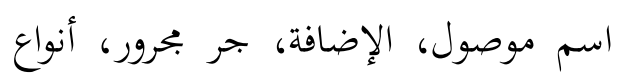

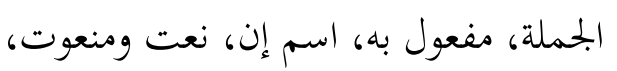
التمييز، الحال، المبتدأ والحبر. أحدها اسم موصول فوجد الباحثة المبندال تركيب اسم موصول في الأية الثالثة "الَّنِيْنَ

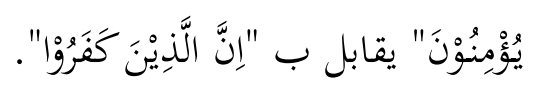

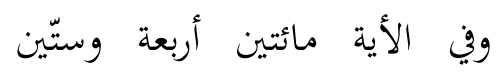

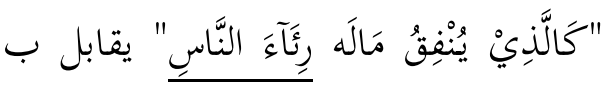

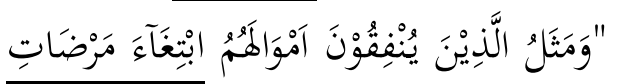

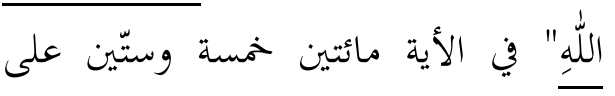
تركيب الإضافة. 
صالح الفضل، علم الأسلوب مبادئه وإجرائته، (قاهرة: دار الشروق، .$p 1991$

عبد الرحمن النجدي، فواصل الآية القرآنية درامة بلاغية دلالية، قاهرة:

$$
\text { مكتبة الآداب، . . . ب م. }
$$

على الجارم ومصطفى أمين، البلاغة الواضحة البيان.المعانى.البديع، قاهرة: دار المعارف، 999 ام. محمد أحمد قاسم ومحي الدين ديب، علوم البلاغة (البديع والبيان والمعاني)، لبانان: المؤسسة الحديث للكتاب، الطبعة الأول، ب. . ب م. محمد صالح شريف عسكري، 10 التقابلات الدلالية في الجزء الثلاثين من القرآن، آفاق الحضارة الإسلامية أكادمية العلوم الإنسانية والدراسات الثقافية، العدد ب الت
بين كلمتين مقابلتين، منها: صلة موصول، مفعول به، جر وبحرور، الإإضافة، مبتدأ وخبر، أنواع الجملة، الحال، تمييز، إسم إن، إنه نعت ومنعوت.

$$
\text { أحمد الهاشمي، جواهر البلاغة في }
$$
المعاني والبيان والبليع، ضبط وتدقيق وتوثيق د. يوسف المصميلي، بيروت: المكتبة العصرية، 999 |م. أحمد مختار عمر، علم الدلالة، قاهرة: مكتبة لسان العرب، طبعة الخامسة .1991 د. بتحاني عمر، ع ا ل بام، بين مغهوم التضاد والطباق عند اللغوبين والبلاغيين، جامعة إبراهيم بدماصي بابنغدا نيجيريا، مالم بحلة الدراسات اللغوية، العدد | 1 . عبر في باله

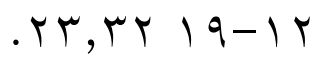




$$
\text { هادي حسن محمد، ظاهرة التضاد في }
$$

المعني، مدرس دكتور في المديرية العامة

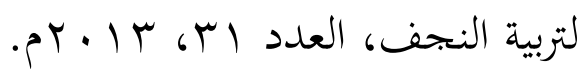
يونس عبد مرزوكك،" المقالة التقابل

$$
\text { اللغظي في القرآن الكريم "دراسة }
$$$$
\text { دلالية، لبنان، بجهول السنة. }
$$

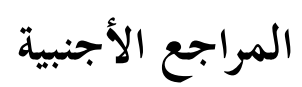

Sugiono, Metode Penelitian

Kuantitatif Kualitatif dan R\&D,

Bandung: Alfabeta,2011.

Lexy Moleong, Metode Penelitian

Kualitatif, Bandung: PT. Remaja

Rosda Karya, 2008.

Suharsimi Arikunto, Prosedur

Penelitian Suatu Pendekatan Praktik, Jakarta: Rineka Cipta, 2012.

Ubaid Ridho, 2017, Sinonim dan Antonim Dalam Al-Qur'an, Jakarta:UIN Syarif Hidayatullah, Jurnal Al-Bayan, Vol.9, No.2. diakses pada 26-11-2019 09.32.

Miftahul Mufid, 2017, Antonim dalam Al-Quran Perspektif Ali AlKhuli (Kajian Semantik dalam Surat Luqman), IAI Sunan Giri Bojonegoro, Jurnal Humaniora, Vol.2, No. 1.

Diakses pada 26-11-19 pukul 09.31.

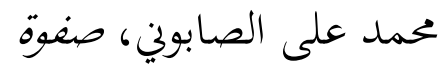

التغاسير، بيروت: دار القرآن الكريم، .$p 1911$

$$
\text { عممد غفران زين العالم، البلاغة في البيان مقرر لصف الرابع كلية }
$$

المعلمين الإسلامية بمعهل دار السلام كونتور للتربية الإسلامية الحلديثة،$$
\text { (فونوروكو : مطبعة دار السلامم، }
$$$$
\text { . . . . }
$$

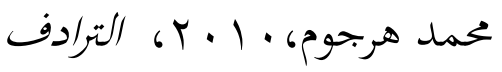

والإشتراك اللغظي والتضاد في اللغة

العربية، بحلة الأدبية جامعة الإسلامية

ألو الدين الحلكومية مكاسار، العدد .1 .

مصطفى الصاوي الجويني، البلاغة

العربية تأصيل وتجلديل، (الاسكاندرية:

. r. t r

مصطفى الغلايين، جامع الدروس العربية، بيروت: دار الرسالة، •r 1 . 